\title{
Production of Biosurfactant by a Marine Alkaliphilic Strain of Pseudomonas aeruginosa and Effect of Various Physico-Chemical Parameters on its Production
}

\author{
Meenal Dukhande', Madhura Warde ${ }^{2}$ \\ ${ }^{1,2}$ Department of Microbiology, G. N. Khalsa College, University of Mumbai, India
}

\begin{abstract}
The effect of temperature and $\mathrm{pH}$ on biosurfactant production by marine alkaliphilic bacterium Pseudomonas aeruginosa was investigated at temperatures from $25^{\circ} \mathrm{C}$ to $45^{\circ} \mathrm{C}$, and $\mathrm{pH}$ 5-10. In this study, biosurfactant production by selected microbe was found to be strongly dependent on $\mathrm{pH}$. The potential of bacterium to utilize different carbon and nitrogen sources for the production of an extracellular biosurfactant was also evaluated. Bacterium grew from pH 6-12 but optimum pH was found to be 9. Similarly it grew at temperature range $25{ }^{\circ} \mathrm{C}$ to $45{ }^{\circ} \mathrm{C}$ and optimum temperature was found to be $30{ }^{\circ} \mathrm{C}$. Strain was able to grow and reduce the surface tension of culture broth to $27.95 \mathrm{~m} \mathrm{~N} / \mathrm{m}$ when cultured using sunflower oil as a sole carbon source and combination of sodium nitrate with peptone as nitrogen source at $\mathrm{pH}$ 9. Strain was found to be alkaliphilic member of biosurfactant-producing Pseudomonas spp, which has potential application in the industrial processes where high $\mathrm{pH}$ is common.
\end{abstract}

Keywords: Biosurfactant, $P$. aeruginosa, alkaliphilic, production, rhamnolipid

\section{Introduction}

Surfactants are surface active agents that reduce the interfacial tension between two liquids, or liquid and a solid. Currently, almost all surfactants used in industry are being derived from petroleum sources by the processes such as sulfonation, ethoxylation, hydroformylation, fractional distillation. Most of the synthetic surfactants have branched side chains as a result they are hardly degraded by microbes and accumulate in environment [1].

In recent years due to environmental hazards associated with synthetic ones microbial production of surfactants has received considerable attention. Biosurfactants are the surface active biomolecules that are intracellularly and extracellularly produced by variety of microorganism.

Pseudomonas spp are known to produce a highly effective biosurfactant which belongs to the class of glycolipid [2]. Glycolipids are the lipids in which carbohydrate moiety is attached to lipid by glycosidic bond. One of the glycolipid that is extracellularly produced by Pseudomonas aeruginosa is rhamnolipid [3].

Many of the biosurfactant producing microbes are found to be hydrocarbon degraders suggesting their role in solubilisation of hydrocarbon substrate and uptake inside the cell.

Glycolipids as a natural product have copious applications in different areas of science. Additionally, some authors showed the ability of glycolipid to emulsify the oil or hydrocarbons. They also possess antimicrobial and antiadhesive activity. So, the glycolipids can be considered as multipurpose agents [4].
As biosurfactants are environmentally safe and thus they are not damaging to human health and ecology. Consumer awareness and adoption of bio-based products and ecofriendly character of biosurfactant encourages the growth of biosurfactant market. In coming few years, global market of biosurfactants will encounter dramatic growth due to multifunctional property of biosurfactants [5].

Large scale production of glycolipid is restricted due to high production cost and low product yield. The major problem is its slow production rate as compared to synthetic surfactant which is mainly because its production is affected by various physical and nutritional parameters. The objective of this study was to study the effect of different physio-chemical parameters on biosurfactant production by alkaliphilic strain of Pseudomonas aeruginosa.

\section{Materials and Methods}

\subsection{Organism and cultivation conditions}

An alkaliphilic bacterium, Pseudomonas aeruginosa isolated from sea water sample from Gateway of India, Mumbai was used for the study. It was found to be capable of producing rhamnolipid type of biosurfactant.

Mineral Salt Medium (MSM) [NaNO3 1.5g/L, KH2PO4 1.0 $\mathrm{g} / \mathrm{L}, \mathrm{MgSO} 4.7 \mathrm{H} 2 \mathrm{O} 0.5 \mathrm{~g} / \mathrm{L}, \mathrm{MnSO} 41.5 \mathrm{~g} / \mathrm{L}, \mathrm{CaCl} 20.02 \mathrm{~g} / \mathrm{L}$, (NH4)2SO4 1.5g/L and FeSO4 $0.01 \mathrm{~g} / \mathrm{L}]$ with $1 \%(\mathrm{v} / \mathrm{v})$ sunflower oil was used for the biosurfactant production by the strain [6].

\subsection{Preparation of inocula}

A loopful of the $24 \mathrm{hrs}$ old culture grown on st. Nutrient agar plate was used to prepare the inoculum. Cell density was adjusted to $0.08 \mathrm{OD}$ at $540 \mathrm{~nm}$ using saline. 


\section{International Journal of Science and Research (IJSR) \\ ISSN (Online): 2319-7064}

Index Copernicus Value (2013): 6.14 | Impact Factor (2015): 6.391

\subsection{Effect of incubation temperature on biosurfactant production}

To study the effect of temperature on biosurfactant production, $100 \mathrm{ml}$ of MSM medium at $\mathrm{pH} 7$ was used. All the media flasks were supplemented with $1 \%(\mathrm{v} / \mathrm{v})$ of sunflower oil. The flasks were inoculated with $1 \%(\mathrm{v} / \mathrm{v})$ inoculum and kept for biosurfactant production under shaking conditions at $140 \mathrm{rpm}$ at different temperature such as $25^{\circ} \mathrm{C}, 30^{\circ} \mathrm{C}, 37^{\circ} \mathrm{C}, 45^{\circ} \mathrm{C}$ for 7 days.

After incubation, the broth of each flask was centrifuged at $10,000 \mathrm{rpm}$ at $4^{\circ} \mathrm{C}$ to pellet the cells and the supernatants were collected. Surface tension of the supernatant was measured by surface tensiometer based on Wilhelmy principle using uninoculated MSM broth as control [7].

The results were expressed in milliNewton per meter $(\mathrm{mN} / \mathrm{m})$. The surface activity of the biosurfactant was expressed in terms of percentage reduction in surface tension which was calculated by the following formula,

Percentage reduction $\quad(\mathrm{ym}-\mathrm{yc})$

in Surface tension $(\%)=$

ym

$\gamma \mathrm{m}=$ surface tension of uninoculated control medium and $\mathrm{\gamma c}=$ surface tension of test supernatant.

\subsection{Effect of $\mathrm{pH}$ on biosurfactant production}

To study the effect of $\mathrm{pH}$ on biosurfactant production, 100 $\mathrm{ml}$ of MSM medium with varying $\mathrm{pH}$ were used. The $\mathrm{pH}$ used was 5.0, 6.0, 7.0, 8.0, 9.0 and 10.0. All the media flasks were supplemented with $1 \%(\mathrm{v} / \mathrm{v})$ of sunflower oil. All the flasks were inoculated with $1 \%$ (v/v) inoculum and kept for biosurfactant production under shaker conditions at $140 \mathrm{rpm}$ at $30^{\circ} \mathrm{C}$ for 7 days. After incubation, broths were centrifuged at $10,000 \mathrm{rpm}$ at $4^{\circ} \mathrm{C}$ to pellet the cells and supernatants were collected. Surface tension of supernatant was measured by surface tensiometer based on Wilhelmy principle and compared with the uninoculated broth.

\subsection{Effect of various carbon sources on biosurfactant production}

To study effect of carbon sources on biosurfactant production, $100 \mathrm{ml}$ of MSM medium at $\mathrm{pH} 9.0$ was used with different carbon sources such as sunflower oil, coconut oil, glycerol $(1 \% \mathrm{v} / \mathrm{v})$ and glucose $(1 \% \mathrm{w} / \mathrm{v})$ and incubated under shaker conditions at $140 \mathrm{rpm}$ at $30^{\circ} \mathrm{C}$ for 7 days.

After incubation, broths were centrifuged at $10,000 \mathrm{rpm}$ at $4^{\circ} \mathrm{C}$ to pellet the cells and supernatants were collected. Surface tension of supernatant was measured by surface tensiometer based on Wilhelmy principle and compared with uninoculated broth.

\subsection{Effect of various nitrogen sources on biosurfactant production}

To study the effect of nitrogen sources on the production of biosurfactant, $100 \mathrm{ml}$ of MSM medium with different nitrogen sources at $\mathrm{pH} 9.0$ was used with sunflower oil (1\% $\mathrm{v} / \mathrm{v})$ as a carbon source and incubated under shaker conditions at $140 \mathrm{rpm}$ at $30^{\circ} \mathrm{C}$ for 7 ndays.

Different nitrogen sources such as ammonium nitrate, ammonium sulfate, peptone, sodium nitrate, tryptone were used in the study.

After incubation period, culture broths were centrifuged at $10,000 \mathrm{rpm}$ at $4^{\circ} \mathrm{C}$ to pellet the cells and supernatants were collected. Surface tension of supernatant was measured by surface tensiometer based on Wilhelmy principle and compared with uninoculated broth.

\section{Results and Discussion}

Strain of Pseudomonas aeruginosa isolated from sea water sample was used and conditions for production of biosurfactant were optimized. Being a biosurfactant it tends to reduce the interfacial tension between two liquids, or liquid and a solid. Therefore reduction in surface tension was inversely correlated to the amount of biosurfactant produced [8]. Surface tension measurement was carried out by dynamic surface tensiometer based on Wilhemy principle that involves the use of thin plate perpendicular to the interphase; force exerted on it by the surface molecules is measured and expressed in terms of milliNewton per meter [9]. All the measurements were expressed in percentage reduction in surface tension of the broth which was directly proportional to the amount of biosurfactant produced [10].

\subsection{Effect of temperature on biosurfactant production by Pseudomonas strain.}

The effect of temperature variation on biosurfactant production was checked at temperatures $25^{\circ} \mathrm{C}, 30^{\circ} \mathrm{C}, 37^{\circ} \mathrm{C}$ and $45^{\circ} \mathrm{C}$. The biosurfactant was produced in temperature range of $25-37^{\circ} \mathrm{C}$ (Table 1 ). Biosurfactant production was found to increase with increase in temperature but the optimum temperature for the biosurfactant production was found to be $30^{\circ} \mathrm{C}$. Graph 1 showed that after $30^{\circ} \mathrm{C}$ the rhamnolipid production sharply decreased. This Pseudomonas strain was unable to grow at $45^{\circ} \mathrm{C}$ thus produced negligible biosurfactant.

Table 1: Effect of temperature on biosurfactant production

\begin{tabular}{|c|c|c|c|c|}
\multicolumn{5}{|c|}{ by Pseudomonas strain } \\
\hline \multirow{2}{*}{$\begin{array}{c}\text { Sr. } \\
\text { no. }\end{array}$} & $\begin{array}{c}\text { Incubation } \\
\text { temperature }\left({ }^{\circ} \mathrm{c}\right)\end{array}$ & \multicolumn{2}{|c|}{ Surface tension $[\mathrm{mN} / \mathrm{m}]$} & \multirow{2}{*}{$\begin{array}{c}\text { \% reduction in } \\
\text { surface tension }\end{array}$} \\
\cline { 3 - 4 } & Control & Test & \\
\hline 1 & $25^{\circ} \mathrm{C}$ & 46.046 & 35.667 & $22.54 \%$ \\
\hline 2 & $30^{\circ} \mathrm{C}$ & 44.196 & 32.61 & $\mathbf{2 6 . 2 0 \%}$ \\
\hline 3 & $37^{\circ} \mathrm{C}$ & 43.361 & 32.17 & $25.80 \%$ \\
\hline 4 & $45^{\circ} \mathrm{C}$ & 46.843 & 40.271 & $14.24 \%$ \\
\hline
\end{tabular}

\subsection{Effect of media pH on biosurfactant production by Pseudomonas strain.}

As all living things are water-based systems hence they heavily depend on aqueous equilibria, especially acid-base equilibria. $\mathrm{pH}$ plays vital role in enzymatic reactions. The $\mathrm{pH}$ of a solution can affect the structure and activity of enzymes [11]. As biosurfactant is synthesized by several enzymatic reactions inside the cells $\mathrm{pH}$, of the medium can affect the enzymes responsible for the synthesis of 


\section{International Journal of Science and Research (IJSR) \\ ISSN (Online): 2319-7064 \\ Index Copernicus Value (2013): 6.14 | Impact Factor (2015): 6.391}

biosurfactant [12]. Production of biosurfactant was checked at different $\mathrm{pH}(5.0-10.0)$. At $\mathrm{pH}$ value 9.0 the optimal production of biosurfactant was observed. At $\mathrm{pH} 9$ surface tension of the broth was reduced to $30.628 \mathrm{mN} / \mathrm{m}$ and $33.849 \%$ reduction in surface tension was observed as shown in table 2. Biosurfactant production at other $\mathrm{pH}$ values was also quantified and the graph was plotted. As shown in graph 2, it can be seen that as the medium $\mathrm{pH}$ is increased from 5.0 to 9.0, biosurfactant production increased, and the optimum production of biosurfactant was obtained at $\mathrm{pH}$ 9.0. Beyond $\mathrm{pH}$ 9.0, decrease in production was observed indicating it to be an alkaliphilic strain. In literature maximum biosurfactant production was found to be at $\mathrm{pH} 7$ by Pseudomonas. Very few studies showed optimum production of biosurfactant by Pseudomonas at $\mathrm{pH}$ 9 [10].

Table 2: Effect of $\mathrm{pH}$ on biosurfactant production by Pseudomonas strain.

\begin{tabular}{|c|c|c|c|c|}
\hline \multirow{2}{*}{$\begin{array}{c}\text { Sr. } \\
\text { no. }\end{array}$} & pH of the & \multicolumn{2}{|c|}{ Surface tension $[\mathrm{mN} / \mathrm{m}]$} & \% reduction in \\
\cline { 3 - 4 } & media & Control & Test & surface tension \\
\hline 1 & 5.0 & 46.561 & 46.012 & $1.17 \%$ \\
\hline 2 & 6.0 & 44.481 & 38.529 & $13.38 \%$ \\
\hline 3 & 7.0 & 46.668 & 39.011 & $16.40 \%$ \\
\hline 4 & 8.0 & 46.47 & 37.931 & $18.37 \%$ \\
\hline 5 & 9.0 & 46.30 & 30.628 & $\mathbf{3 3 . 8 4 9} \%$ \\
\hline 6 & 10.0 & 42.42 & 30.186 & $28.84 \%$ \\
\hline
\end{tabular}

3.3 Effect of carbon sources on biosurfactant production by Pseudomonas strain

Micro-organisms have difficulties in utilizing water immiscible substrates like oil because of their low water solubility. Water immiscible substrates are either taken up directly by efficient transportation across cell membrane or by producing certain extracellular solubilizing factors, solubilization or emulsification, resulting into hydrocarbon uptake. One of such extracellular solubilizing mediator is biosurfactant [12]. Type of carbon source influences the quantity of biosurfactant produced [13].

As depicted in graph 3, Sunflower oil was found to be the optimum hydrophobic carbon source for inducing rhamnolipid synthesis. When sunflower oil was used $26.182 \%$ reduction in surface tension of broth was observed as shown in table 3 .
Table 3: Effect of various carbon sources on biosurfactant production by Pseudomonas strain

\begin{tabular}{|c|c|c|c|c|}
\hline Sr. & Carbon & \multicolumn{2}{|c|}{ Surface tension $[\mathrm{mN} / \mathrm{m}]$} & \% reduction in \\
no. & sources & Control & Test & surface tension \\
\hline 1 & Sunflower oil & 46.02 & 33.971 & $\mathbf{2 6 . 1 8 2 \%}$ \\
\hline 2 & Coconut oil & 44.558 & 35.707 & $19.86 \%$ \\
\hline 3 & Glycerol & 43.671 & 33.046 & $24.33 \%$ \\
\hline 4 & Glucose & 39.485 & 29.511 & $25.26 \%$ \\
\hline
\end{tabular}

\subsection{Effect of nitrogen sources on the biosurfactant production by Pseudomonas strain.}

Different nitrogen sources such as peptone, ammonium sulphate, sodium nitrate, ammonium nitrate, tryptone were explored for their effect on biosurfactant production. Out of the five nitrogen sources used sodium nitrate, peptone and ammonium sulphate were found to be most promising for the biosurfactant production. In literature it was found that nitrates supports maximum production of biosurfactant in $P$. aeruginosa [14].

The agreement between our findings and those in the literature suggests that nitrate tends to stimulate biosurfactant production. As sodium nitrate gave high yields (35.045\% reduction), different combinations of sodium nitrate with peptone and ammonium sulphate were tried as shown in table 4. Combination of inorganic source i.e. sodium nitrate with organic source i.e. peptone reduced surface tension of broth by $37.502 \%$ as shown in graph 4 .

Table 4: Effect of various nitrogen sources on production of biosurfactant by Pseudomonas strain

\begin{tabular}{|c|c|c|c|c|}
\hline Sr.no. & Nitrogen sources & \multicolumn{2}{|c|}{$\begin{array}{c}\text { Surface tension } \\
{[\mathrm{mN} / \mathrm{m}]}\end{array}$} & $\begin{array}{c}\text { \% reduction in } \\
\text { surface tension }\end{array}$ \\
\cline { 3 - 4 } & & $\begin{array}{c}\text { Control } \\
\text { Sest }\end{array}$ & \\
\hline 1. & Sodium nitrate & 47.864 & 31.045 & $35.139 \%$ \\
\hline 2. & Ammonium nitrate & 44.708 & 36.386 & $18.61 \%$ \\
\hline 3. & Peptone & 48.88 & 31.159 & $36.254 \%$ \\
\hline 4. & Ammonium sulfate & 46.075 & 31.826 & $30.92 \%$ \\
\hline 5. & $\begin{array}{c}\text { Sodium nitrate + } \\
\text { Ammonium sulfate }\end{array}$ & 48.40 & 31.775 & $35.36 \%$ \\
\hline 6. & $\begin{array}{c}\text { Sodium nitrate }+ \\
\text { peptone }\end{array}$ & 44.398 & 27.748 & $\mathbf{3 7 . 5 0 2 \%}$ \\
\hline 7. & Tryptone & 43.182 & 30.871 & $28.51 \%$ \\
\hline
\end{tabular}


International Journal of Science and Research (IJSR)

ISSN (Online): 2319-7064

Index Copernicus Value (2013): 6.14 | Impact Factor (2015): 6.391

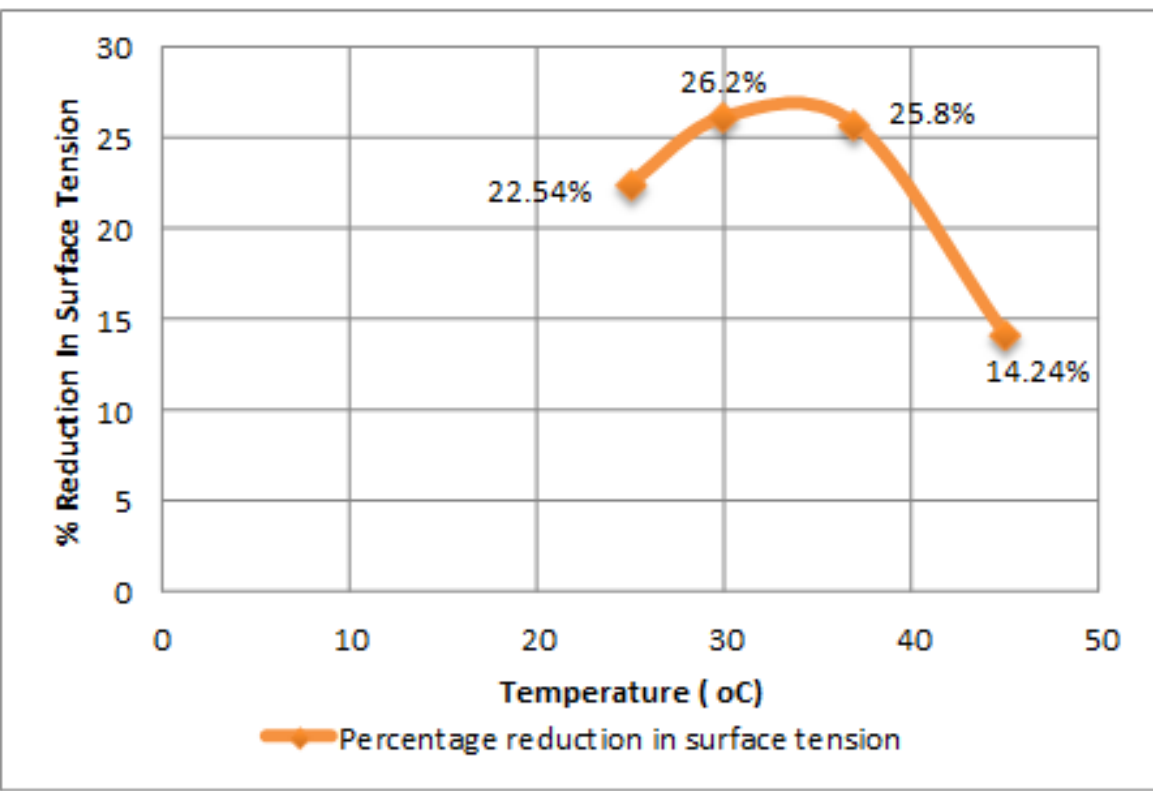

Graph 1: Effect of temperature on the production of biosurfactant by Pseudomonas strain

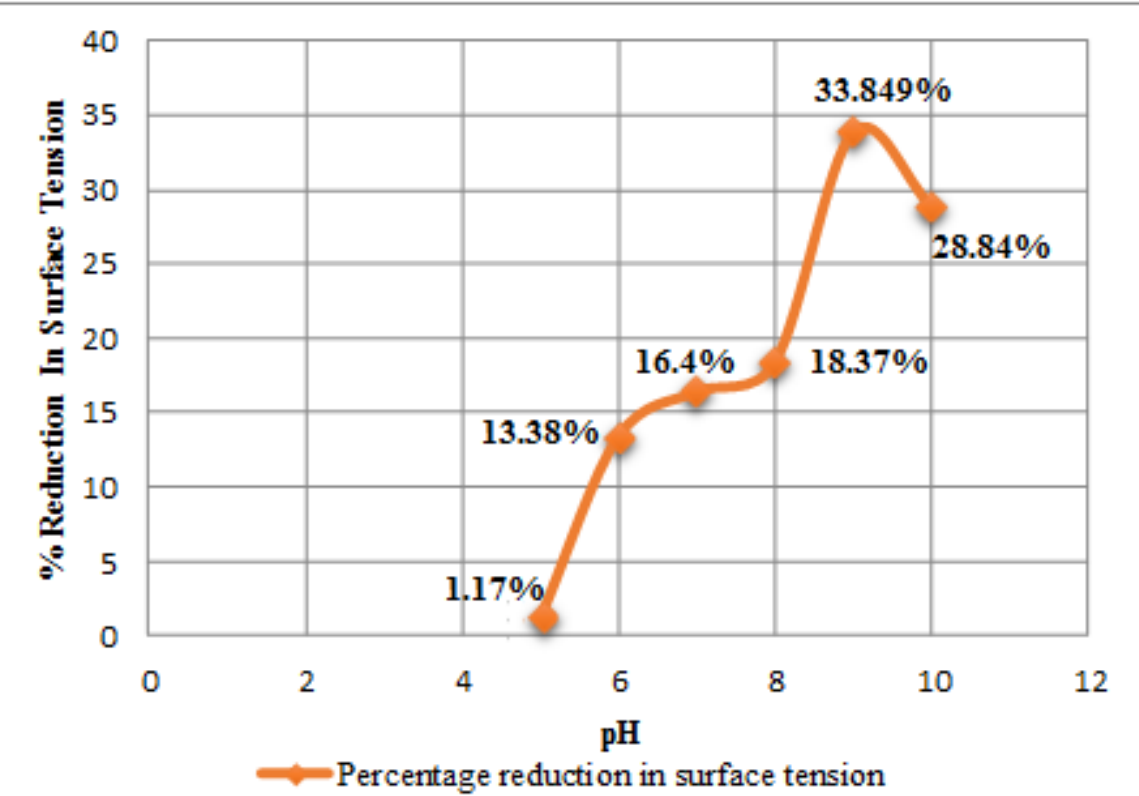

Graph 2. Effect of $\mathrm{pH}$ on the production of biosurfactant by Pseudomonas strain.

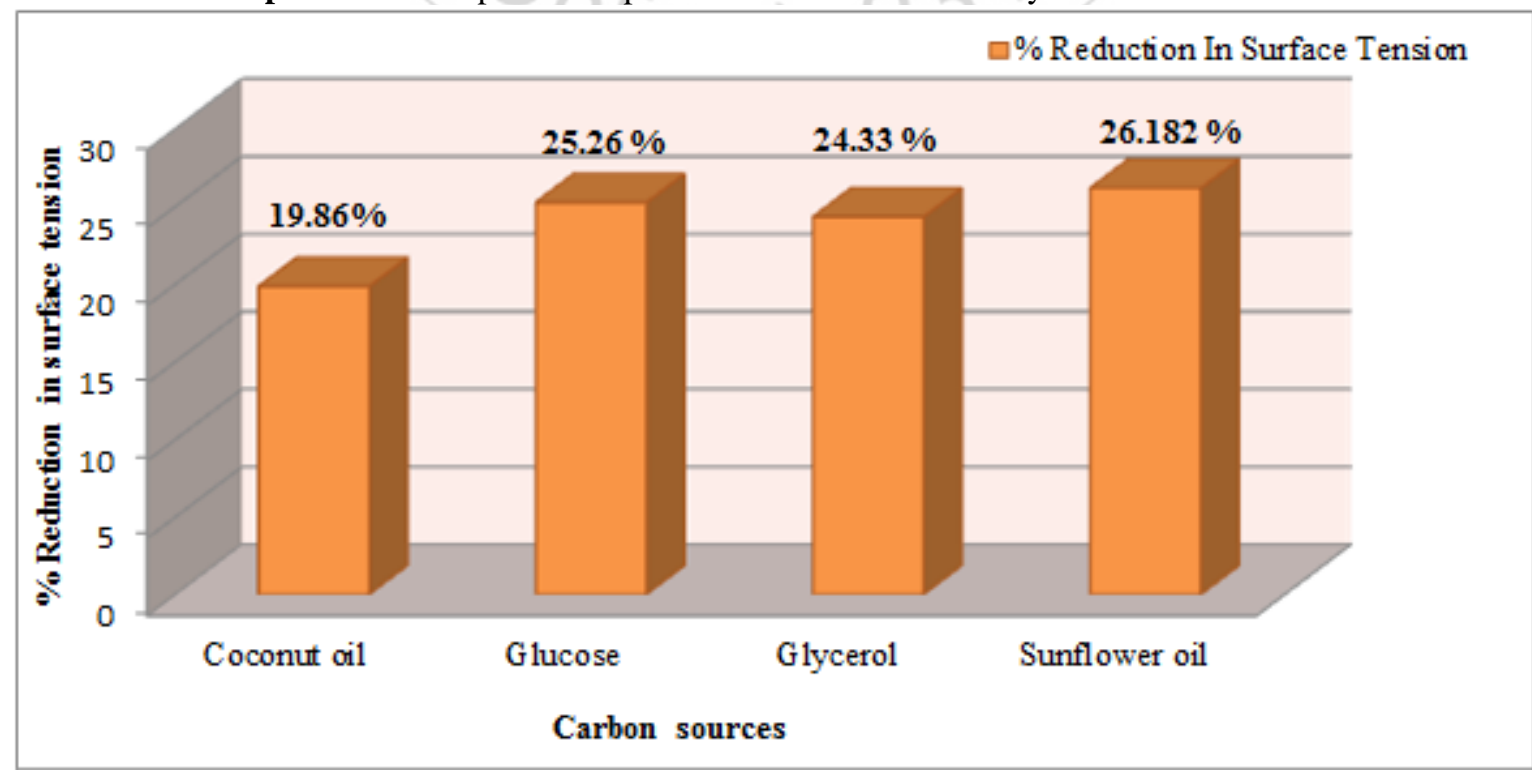

Graph 3: Effect of various carbon sources on biosurfactant production by Pseudomonas strain.

Volume 5 Issue 5, May 2016 www.ijsr.net 


\section{International Journal of Science and Research (IJSR) \\ ISSN (Online): 2319-7064}

Index Copernicus Value (2013): 6.14 | Impact Factor (2015): 6.391

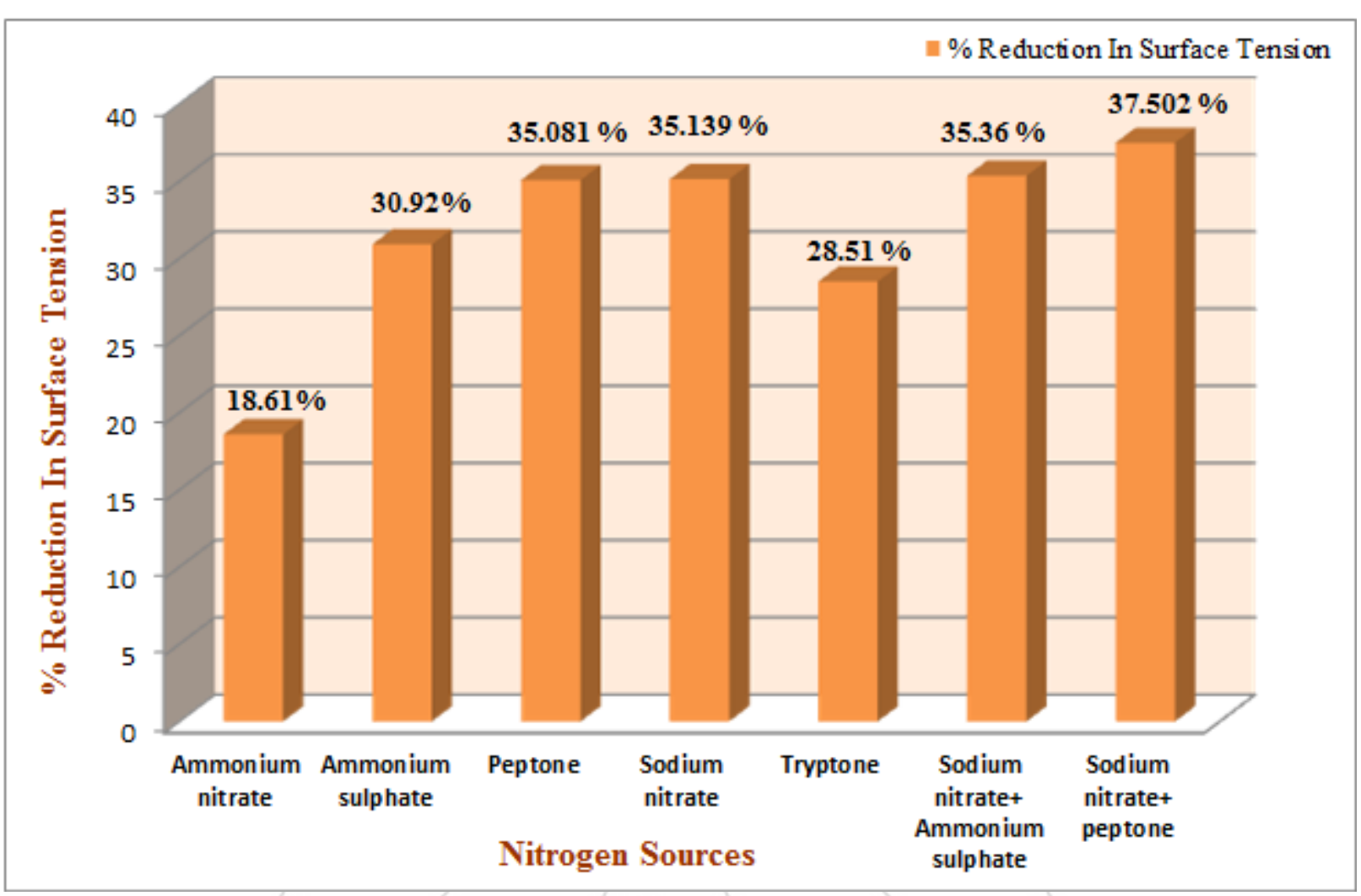

Graph 4: Effect of various nitrogen sources on biosurfactant production by Pseudomonas strain

\section{Conclusion}

The work presented in this paper mainly focuses on biological synthesis of biosurfactant produced under alkaline conditions using Pseudomonas aeruginosa as the producer organism. The production of biosurfactant was carried out under shake flask conditions. Effect of various physiochemical parameters like $\mathrm{pH}$, temperature, carbon sources and nitrogen sources on the production of biosurfactant were studied and optimized by measuring surface tension of the broth. These parameters play an important role in the cellular metabolism and in turn affect the biosynthesis of biosurfactant. The production of biosurfactant was found to be highly dependent on $\mathrm{pH}$ of the medium giving high yield at $\mathrm{pH}$ 9.0. High production cost can be tolerated for biosurfactants used in low volumes in specialty markets such as cosmetics and health care. Therefore the use of pure sunflower oil for production of biosurfactant can be beneficial for such application fields wherein the high cost production is balanced by its requirements in low volumes.

\section{Future Scope}

This study opened the opportunity for investigating the potential of biosurfactant as an anti bacterial, antifungal and antiviral agent. Its application in cosmetics formulations can be investigated as an alternative to SLS/ SDS. Cheap raw materials like Sunflower oil cake, ground nut oil cake, bagasse and vegetable waste can be used for fermentation. Sunflower oil cake is the solid by-product from the sunflower oil extraction process and an important pollutant waste because of its high organic content which can be used for production of biosurfactant.

\section{Acknowledgment}

The authors wish to thank the G. N. Khalsa College for providing necessary laboratory infrastructure to carry out the work. They are also thankful to Dr. Vinay Juvekar and Mr. Shyam Kedar of the organic processes laboratory at Indian Institute of Technology (IIT), Bombay for their help with the surface tension analysis.

\section{References}

[1] Radhika Chandankere, Jun Yao , Kanaji Masakorala, A.K.Jain and Ranjan Kumar, "Enhanced production and characterization of biosurfactant produced by a newly isolated Bacillus amyloliquefaciens USTBb using response surface methodology," IJCMAS, vol. 3 number 2, pp. 66-80, 2014.

[2] Ellaiah P, Prabhakar T, Sreekanth M, Taleb AT, Raju $\mathrm{PB}$, Saisha V, "Production of glycolipids containing biosurfactant by Pseudomonas species", Indian J Exp Biol. 2002 Sep;40(9):1083-6.

[3] T. A. A. Moussa, M. S. Mohamed and N. Samak, "Production and characterization of di-rhamnolipid produced by Pseudomonas aeruginosa tmn", Brazilian Journal of Chemical Engineering, Vol. 31, No. 04, pp. $867-880$

[4] I. M. Banat á R. S. Makkar á S. S. Cameotra, "Potential commercial applications of microbial surfactants", Appl Microbiol Biotechnol (2000) 53: 495-508, November 1999.

[5] Biosurfactants Market - Global Scenario, Raw Material and Consumption Trends, Industry Analysis, Size, Share and Forecasts 2011 - 2018, 20th july 2012. 


\section{International Journal of Science and Research (IJSR) \\ ISSN (Online): 2319-7064}

Index Copernicus Value (2013): 6.14 | Impact Factor (2015): 6.391

[6] Meenal Dukhande, Madhura Warde, "Isolation and Characterization of Potent Biosurfactant Producing Bacteria from Petroleum Contaminated Soil and Sea Water", IJERT Vol. 5 Issue 03, March-2016.

[7] Orathai Pornsunthorntawee, Nampon Arttaweeporn, Sarawut Paisanjit, Pastra Somboonthanate, Masahiko Abe, Ratana Rujiravanit, Sumaeth Chavadej, "Isolation and comparison of biosurfactants produced by Bacillus subtilis PT2 and Pseudomonas aeruginosa SP4 for microbial surfactant-enhanced oil recovery", Biochemical Engineering Journal, Volume 42, Issue 2, 1 November 2008, Pages 172-179.

[8] Aparna A, Srinikethan G, Smitha Hegde, "Effect of addition of biosurfactant produced by Pseudomonas sps. on biodegradation of crude oil" IPCBEE vol.6 (2011).

[9] https://en.wikipedia.org/wiki/wilhemy principle.

[10] Ainon Hamzah, Noramiza Sabturani \& Shahidan Radiman, "Screening and optimization of biosurfactant production by the hydrocarbon-degrading bacteria" Sains Malaysiana 42(5)(2013): 615-623.

[11]David E. Sadava, H. Craig Heller, Gordon H. Orians, William K. Purves, David M. Hillis, "E-Book for Life: the Science of Biology", 161-162.

[12] Max m. Burger, Luis Glaser, and Robert Main Burton, "The Enzymatic Synthesis of a Rhamnose-containing Glycolipid by Extracts of Pseudomonas aeruginosa", The Journal Of Biological Chemistry Vol. 238, No. 8, August 1963.

[13] N. G. K. Karanth, P. G. Deo and N. K. Veenanadig, "Microbial production of biosurfactants and their importance"

[14] A.R. Najafia, M.R. Rahimpour, A.H. Jahanmiri, R. Roostaazad, D. Arabian, M. Soleimani, Z. Jamshidnejad, "Interactive optimization of biosurfactant production by Paenibacillus alvei ARN63 isolated from an Iranian oil well" Colloids and Surfaces B: Biointerfaces Volume 82, Issue 1, 1 January 2011, Pages 33-39.

[15] M. Irfan Maqsood and Asif Jamal, "Factors affecting the rhamnolipid biosurfactant production". Pak. J. Biotechnol. Vol. 8 (1) 1-5, 2011.

\section{Author Profile}

Dr. Meenal Dukhande is a Assisant professor of Microbiology at G. N. Khalsa College of Arts, Commerce and Science, University of Mumbai. She has coauthored over 4 publications including research on lipases and biosurfactant. She is a recognized guide for the phD in Microbiology. she currently has two research scolars under her working on Microfliudics and E-waste biomediation.

Ms. Madhura Warde obtained her bachelor's degree in Microbiology from Smt. CHM college, University of Mumbai in 2014. She is currently a Masters student under the supervision of Dr. Meenal Dukhande at G. N. Khalsa College of Arts, Commerce and Science. Her research is centered on production of biosurfactant by potent biosurfactant producing bacteria, its optimization and application. 